\title{
Peer Rejection among Children with Conduct Disorder: Compare Cognitive-Behavioral Therapy and Behavioral Parent Training
}

\author{
Somaieh Salehi ${ }^{1,2 *}$, Saeed Ghanbari ${ }^{1}$, Sepideh Shaban ${ }^{1,2}$ and Mino Pooravari \\ ${ }^{1}$ Faculty of Psychology and Educational Studies, Shahid Beheshti University, Tehran, Iran \\ ${ }^{2}$ Faculty of Educational Studies, Universiti Putra Malaysia, Selangor, Malaysia
}

\begin{abstract}
This study aims to compare Making Choices program and Barkley Behavioral Parent Training on the peer rejection of Iranian children with Conduct Disorder. A total of 136 Iranian children between 8 and 10 years old with Conduct Disorder participated in the study. The peer rejection questionnaire was used to check the results of educating. Making Choices program to children and Barkley Behavioral Parent Training to parents of them. The results of the analysis of repeated measure Anova revealed a significant difference between, Making Choices program, Behavioral Parent training, and a combination of two programs. It showed that three kinds of interventions include Making Choices program, Barkley Behavioral Parent Training and combination of both interventions resulted in decreasing of peer rejection in same level at the time of follow up. It is suggested that the combination of both programs is more effective in a short period of time. However, both kinds of interventions decreased peer rejection of children with Conduct Disorder in a long period of time. The time of follow-up indicated that peer rejection of children decreased more in the group with the combination of both programs. It is recommended to carry out an investigation and compare the teacher and parent rating on symptoms of children with Conduct Disorder.
\end{abstract}

\section{Introduction}

According to DSM-V, Conduct Disorder (CD) is one of the important forms of externalizing disorder. The main symptoms of Conduct Disorder include aggression, impulsive, and deceitful behavior [1]. DSM-V explains that CD is recognized by persistent patterns of behavior that violates the basic rights of others or major age-appropriate societal norm [1]. In DSM-5, the criteria for CD are largely unchanged from DSM-IV. According to DSM-5 "The specifier applies to those individuals with more serious pattern of behavior characterized by a callous and unemotional interpersonal style across multiple settings and relationships" [2]. The prevalence of this disorder is between $6 \%$ and $16 \%$ for boys and between $2 \%$ and $9 \%$ for girls [3]. The Iranian study reported that $10.5 \%$ of primary school students in Iran affected by this disorder. Children with $\mathrm{CD}$ often use aggressive behavior to respond to other peers and people [4]. These children suffer of their own behaviors, consume the most expensive resources of the society, and create problems for themselves, their families, peers, and teachers at school [5].

Conduct Disorder with its patterns of disturbed behavior is recognized with two types includes childhood-onset type and adolescent-onset type under the classification of DSM-V. When at least one symptom of the disruptive behaviors of $\mathrm{CD}$ among children that listed in DSM-V emerges under 10 years old, it is classified as childhood-onset type of Conduct Disorder. Those children who do not exhibit any symptoms and serious problems of CD under 10 years old, and show at least three symptoms of oppositional behavior, academic, social, or community problems most in the environment after this age, are categorized as adolescent-onset type of Conduct Disorder [1].

Another important problem of children with Conduct Disorder is not enough opportunity for the development of social skills in their interpersonal relationship. They often reject by their peers and face with negative feedback in the classroom by teachers. Using aggressive behavior in children with Conduct Disorder leads to decrease the chance of friendship with children with prosocial behavior, get close to children with deviant behavior, and develop the antisocial behavior among them [6].

Treatments for children with Conduct Disorder contain pharmacotherapy, Cognitive Behavioral Therapy (CBT), and Behavioral Parent Training [7]. Pharmacotherapy is not considered as the only treatment especially for those children with Conduct Disorder who have another disorder for instance anxiety disorder [8]. Cognitive Behavioral Therapy focuses on interpersonal-problem solving and social cognition to help in the treatment of peer problems in children with Conduct Disorder [9]. Problem-Solving Skills Training (PSST), Social Skills Training, Cognitive Problem-Solving Skills Training, Making Choices program, and Incredible Years Training with the child training program are the programs based on CBT that targets Conduct Disorder and specifically interpersonal difficulties of these children [10]. PSST targets antisocial behavior and leads to solve cognitive deficits of children in short term and long term. The finding of the study showed that disruptive behavior decreased among elementary school-aged children by conducting PSST [10]. This study demonstrated on the maintaining of decreasing disruptive behavior and improving prosocial behavior after two-year follow-up. Social Skills Training with specific procedures such as modeling, behavioral rehearsal, and feedback emphasizes on training social skills for decreasing negative behaviors [11]. Another study examined the effects of Social Skills Training based on CBT techniques on aggressive and disruptive behavior of primary school children. The outcomes of the study revealed that this training program results in decreasing aggression and disruptive behavior among children [12].

Making Choices program is a kind of social-problem solving skills that influences on aggression and peer difficulties of children with conduct problems. This program focuses on children's deficits in Social

*Corresponding author: Somaieh Salehi, Phd of Counseling, Shahid Beheshti University, Tehran, Iran; Tel: 989126076770; E-mail: somaieh19salehi@gmail.com

Received April 24, 2014; Accepted July 12, 2014; Published July 21, 2014

Citation: Salehi S, Ghanbari S, Shaban S, Pooravari M (2014) Peer Rejection among Children with Conduct Disorder: Compare Cognitive-Behavioral Therapy and Behavioral Parent Training. Arts Social Sci J 5: 070. doi: 10.4172/21516200.1000070

Copyright: () 2014 Salehi S, et al. This is an open-access article distributed under the terms of the Creative Commons Attribution License, which permits unrestricted use, distribution, and reproduction in any medium, provided the original author and source are credited. 
Information Processing and creates the situation for children for better thinking about social situation, making social goals and alternative responses to new social situations [13]. It is offered with or without some lessons for a family that is called Strong Families (SF). This program conducted for children in various studies from 1994 to 2011. The result of the study on 443 children in public elementary school in $3^{\text {rd }}$ grade showed decreasing aggression after the program and 6 month follow-up [14]. The study of Conner and Fraser showed the effects of Making Choices program and Strong Families for 67 preschool. The results of this study showed improvement in peer acceptance and decreasing of aggressive behavior [15].

Parents of children with Conduct Disorder often use "Coercive cycle" and it results in aggravating oppositional behavior among children [16]. Parents of these children use some behaviors such as yelling or nagging at children for asking to stop the disruptive behavior of children. However, it is a negative reinforcement for children. Kazdin explained that Behavioral Parent Training effects on behavior modification for parents of children with Conduct Disorder on the basis of social learning principles [7]. Parent Management Training is an important kind of Behavioral Parent Training in individual and group setting for children with Conduct Disorder. Programs based on PMT include Helping the Noncompliant Child, Incredible Years Parent Training Series, Triple P-Positive Parenting Program, and Barkley Parent Training Program [17].

One of the programs based on PMT that is called Helping the Noncompliant Child designed by Forehand and McMahon. This program is appropriate for the noncompliance behavior of children between 3 and 8 years old in two phases. The first phase is "Differential attention phase" for education by conducting effective verbal attention and using the positive physical feedback of parents to their children. The second phase is "Active ignoring" that the parents are educated how to use effective principles for minor inappropriate behavior of children in order to result in child compliance of children. This program showed effective results in declining disruptive behavior and aggression after 14 years follow up [18].

The parent training of the Incredible Years Series contains a BASIC program for parents of children in different age range from infant to children with 13 years old. In addition, this program has specific training based on the level of risk for the children divided in level one for parents of young children, level two for parents to provide educating skills to parents for flexible environments at home, level three for parents of children at high risk without the diagnosis of Conduct Disorder or Oppositional Defiant Disorder, and level four for parents of children with symptoms of disorders [19]. One study stated that conducting the ADVANCED program of the Incredible Years Series for parents of children affects on marital conflicts, anger, poor problem solving skills, and coercive behavior in parent - child relationship [20]. The Triple P-Positive parenting program is another kind of PMT developed by Dr. Matthew Sanders and his colleagues at the University of Queensland in Brisbane, Australia. The aim of this program is to improve the parents' skills for children under 12 years old to control dysfunction between children [21]. The other results of this parent training in family environment include decreasing depression and stress, and progress of marital satisfaction. This program divided into five levels based on the dysfunction of children. Children with severe behavioral problems and also the coercive style of the family need to join to the level 5 of the program to get benefits for both child and family. The other study conducted for the examining the effects of the StandardLevel 4, Enhanced-Level 5 and Self-Directed-Level 4 on families with disruptive children. The results of this study demonstrated decreasing in disruptive behavior for children in the third year of follow-up [22].

Barkley Behavioral Parent Training is another kind of parent training for children with noncompliant behavior between 2 and 12 years old. Parents of children with social aggressive behavior, oppositional, and defiant behavior can benefit from this program. The aim of this program is to focus on parent management skills by teaching social learning principles for parents of children with ADHD, ODD, and CD to improve their awareness about managing children's behavior and solving family conflicts [23]. Barkley indicated about importance of some characteristics of parents include cognitive problems, marital status, and parent-child communication to effect on the changing defiant behavior of children [24]. It is reported that 55 to $70 \%$ of studies based on this parent training revealed successful results with maintenance of the effects for both parents and children and less costly material and supplements.

There are few studies in Iran based on Cognitive-Behavioral Therapy and Behavioral Parent Training for children with conduct problems. These studies mainly focused on Cognitive Behavioral Therapy such as the study of Baedi [25] to examine the effects of play therapy on the basis of Cognitive-Behavioral group Therapy for children with aggressive behavior between 7 and 11 years old, the study of Tuisarkani-Ravari [26] to determine the effects of social skills training based on storytelling between 22 girls at primary school between 10 and 11 years old with Conduct Disorder, the other study to evaluate the effects of group therapy based on Cognitive Behavioral play therapy for aggressive children between 8 and 11 years old [27], the later study to examine the effects of group therapy in parent-child relationship on aggression in pre-school children with aggressive behavior [28], and the additional study to determine the effects of Problem-Solving Skills Training and Parent Management Training among 40 students between 10 and 11 years old with CD [29]. Overall, the results of above studies showed that Cognitive-Behavioral Therapy was effective for decreasing aggressive behavior and improvement in social skills. Another study reported that parent training based on the Adlerian approach affected on coping methods of parents of children with Conduct Disorder and decreased the severity of Conduct Disorder among children [30].

In summary, according to the brief literature reviewed above, there are rarely systematic studies regarding the effects of CognitiveBehavioral Therapy especially to impact peer difficulties of children with conduct problem in Iran.

As it mentioned above, according to the recent statistics of children with Conduct Disorder, the number of children affected with this disorder is increasing around the world and in Iran [31]. In addition, children with childhood onset type of $\mathrm{CD}$ show more aggressive behavior and consequently peer problems [7]. Children with conduct problems who experience aggressive behavior are at high risk of other interpersonal difficulties particularly peer rejection, school dropout, delinquency, and violence. Thus, they have less opportunity for developing social skills compare with other children [32].

As it reviewed in this section, Making Choices program effects on peer rejection among Cognitive-behavioral interventions for children with conduct problems. The developers of this program suggested for the stronger parenting program for children are at high risk of conduct problems [13]. As the family environment of these children needs to modify, and Barkley Behavioral Parent Training is the effective and less costly program for children with $\mathrm{CD}$, this study aims to examine 
and compare the effects of the Making Choices program, Barkley Behavioral Parent Training, and combination of both programs on peer rejection among children with Conduct Disorder to add the body of knowledge in Iran and around the world. The research question of the study is as follows:

Is there significant difference between mean scores of peer rejection in groups with MCP, BBPT, the combination of both programs and control group among children with $\mathrm{CD}$ across pre-test, post-test, and follow-up?

The research hypothesis of the study is listed below:

$\mathrm{H}_{01}$ : There is no significant difference between mean scores of peer rejection in the groups with $\mathrm{MCP}, \mathrm{BBPT}$, the combination of both programs and control group among children with CD across pre-test, post-test, and follow-up.

Operationalized working hypothesis: Peer rejection of children with $\mathrm{CD}$, aged 8-10 years will change when they participate in group MCP in first group, or their parents participate in group with BBPT, or children and their parents participate in the combination of both programs.

To this end, this paper is characterized as follows: (1) Section 2 provides the research method applied in this study, (2) results of the study are presented in Section 3, (3) finally, Section 3 gives the discussion related to the hypotheses, and conclusion in terms of limitations and suggestions for future researches.

\section{Research Method}

\section{Research design}

The true experimental design was used to examine the effects of the Making Choices (MC) program and Barkley Behavioral Parent Training (BBPT) on peer rejection of children with CD. The randomized, pre-test, post-test, control group design under the category of true experimental design conducted for the current study. According to the study by some scholars the greatest internal validity is provided by true experimental design especially in social science [33]. There are four groups in this study includes three experimental groups and one control group. The researchers manipulated the independent variable in true experiments through treatment and comparison condition(s) and conducts high degree of control. All participants have the same chance of being in the experimental and control groups through doing random assignments of subjects. Random assignment of subjects makes the groups equivalent to all important dimensions. So, no systematic differences were found between the groups. The main threat of internal validity is History. It refers to special events arise throughout the study and make changes in the dependent variable. This threat can be controlled through using control group.

The pre-test was conducted for all participants in the first week of the study before starting the treatments for experimental groups. The post-test also applied in the last session of the programs in experimental groups for all of the participants. This study also had the follow-up three months after conducting the interventions. This time allows investigators return to participants at a later of time to followup on initial results. This period allows time to see any changes of peer rejection among children with $\mathrm{CD}$. In addition, it shows the results of manipulating independent variables (interventions) in long period of time beside the end session of interventions.

\section{Population and sample}

The target populations of this study are children (boys and girls) with $\mathrm{CD}$ in Tehran/Iran between 8 and 10 years old. One hundred and thirty six children (boys and girls) between 8 and 10 years old with childhoodonset type of Conduct Disorder were selected from the centers under the license of rehabilitation organization and educational-vocational organization in Tehran/Iran by random assignment. Each group in this study contains 34 participants. The first group received only Making Choices program with 34 children with childhood-onset type of $\mathrm{CD}$; the second group which was parents of 34 children with childhoodonset type of CD received only Barkley Behavioral Parent Training; the third group received Making Choices program for children and Barkley Behavioral Parent Training for parents of children; and the fourth group which is control group received no intervention. It is worth mentioning that as it was the first time of conducting both of the treatments in Iran for children with Conduct Disorder; so both Making Choices program and Barkley Behavioral Parent Training applied for few children and parents of children with Conduct Disorder as the pilot study. Thus, the problems and feedbacks of parents and children were collected to consider in the real study.

\section{Requirement and informed consent}

Parents of children invited one session before starting the program to confirm of participating themselves or bring their children to join the program. The written agreement obtained from the main center under the license of rehabilitation organization and educationalvocational organization in Tehran.

\section{Instruments}

The psychiatrist of the center conducted a Structured Clinical Interview with both children and their parents to select children with Conduct Disorder and childhood-onset type based on DSM-V criteria. The psychiatrist checked the following criteria for the participants of the study: (i) moderate severity of $\mathrm{CD}$, (ii) childhood-onset type of $\mathrm{CD}$, (iii) the age between 8 and 10 years old, (iv) normal intelligence, (v) no comorbidity with Attention Deficit Hyperactivity Disorder and Learning Disorder, (vi) receiving no medication and other treatments during the past six months by children and parents, (vii) social information processing levels of children, and (viii) no illness of parents.

Child Behavior Checklist (CBCL) is completed by parents of children to recognize the severity of Conduct Disorder. This form is suitable for children between 6 and 18 years old. The first part of this form includes basic information, rating of educational proceeds, and rating for few sides of adaptive functioning. The next part is composed of 118 items for problem behavior checklist [34]. The following syndromes are recognized by CBCL: anxious/depressed, withdrawn/depressed, somatic complaints, social problems, thought problems, rule breaking behavior, and aggressive behavior. In addition, CBCL is scored on the following Diagnostic and Statistical Manual of Mental Disorder (DSM) -oriented scales: Affective problems, Anxiety problems, Somatic problems, Attention Deficit Hyperactivity problems, Oppositional Defiant problems, and Conduct problem. Minai adapted three scales of Achenbach System of Empirically Based Assessment (ASEB) includes CBCL (Child Behavior Checklist), TRF, and YSR (Youth Self Report) in Tehran/Iran for 1437 students (748 boys and 689 girls) [35]. Achenbach and Rescola stated that the validity of CBCL items has been maintained by four decades of research through around 100 investigators in the current researches [34]. Content validity, 
criterion-related validity, and construct validity measured for CBCL by in Iran [35]. The result of the numeric evidence of content validity based on discrimination of questions in Iran showed that the numeric evidence of content validity of a Conduct Disorder scale based on the DSM oriented scale is .82 for girls and .83 for boys. The reliability the Conduct problem of CBCL reported .93 [34]. Minai measured the reliability for the Conduct problem of CBCL is .72 for children between 6 to 11 years and .76 for children between 12 to 18 years [35].

The peer rejection questionnaire used to identify the peer rejection of children with Conduct Disorder. This questionnaire was created by Tahmasian for measuring peer rejection and peer acceptance among Iranian students. She was created this questionnaire based on sociometric questionnaire (based on the questions of who likes you the most in the class and who likes you the least in the class), consulting with teachers, and a group of clinical psychologists [36]. This questionnaire consists of 15 items that is filled by students. Tahmasian reported the reliability of the instrument firstly, among high-school students of .91 with Cronbach's Alpha [36]. Another study assessed the reliability of instrument among 127 elementary school students between 7 and 12 years old as .83 with Cronbach's Alpha [37]. The construct validity of the instrument was confirmed through clinical psychologist group and sociometric questionnaire [36]. The validity of the instrument was reported as .93 through test-retest in this study.

\section{Procedures}

Children with Conduct Disorder received the Making Choices (MC) program two times weekly for ten weeks. This program aimed to teach children how to interact with each other in a cooperative manner by enhancing alternatives, formulate social goals and social responses in different social situations. While they learn this issue, steps of problemsolving explained for them. According to this program childhood aggression and peer difficulties connect to the deficit in each step of social information processing [14]. In this program problem-solving sequence is thought in order to utilize it with difficult social situations. Children practice the skills of problem-solving by interactive play activities. The leaders of this program are free to make any changes in the activities as it based on the goals of the Making Choices program. In each lesson to children first the previous one overviewed, and then new skill is educated through activities. Each lesson is short and consistently structured [13]. The purpose of the group is introduced to children with the appropriate language based on their age and the content of the Making Choices program. Social information processing steps include: (1) encoding of cues (2) interpretation of cues (3) clarification of goals (4) response access or construction (5) response decision, and (6) behavioral enactment [38]. It is reported that children with Conduct Disorder encoded less cues in comparison with normal children [39].

The Barkley Behavioral Parent Training (BBPT) that was educated to parents of children in this study called "Defiant Children". This program was educated to parents of children with Conduct Disorder for 2 hours, weekly for 10 weeks. The program designs are trained to participants in behavioral and social learning principles. Parent-child interaction style, increasing compliance of children, paying enough attention to child behavior, positive reinforcement system for instance token economy, and disciplinary method are educated to parents in order to handling behavior problems of children. Each session was held with the reviewing of the previous session, displaying the new skills, teaching new behaviors to parents, practicing parents' new skills, and reviewing the assignment [24].

\section{Data Analysis}

To test the hypothesis the data were analyzed quantitatively with both descriptive and inferential statistics.

The skewness value of peer rejection for group 1 (group with MC program) is -1.04 in pre-test, .72 in post-test, and .69 in follow-up. Since the value of skewness for group 1 in pre-test, post-test, and follow-up is between -2 and +2 , we can determine for the normal approach of distribution for peer rejection in this group [40] [41]. Similarly, the skewness value in group 2 (group with BBPT program) is .54 in pretest, .12 in post-test, and .691 in follow-up. Because the skewness value in this group in pre-test, post-test, and follow-up is between -2 and +2 , we can conclude that there is normal distribution for this group. The skewness value in group 3 (group with combination of MC program and BBPT program) is -.74 in pre-test, .08 in post-test, and .10 in follow-up. The skewness value in this group is also between -2 and +2 ; so we can state that there is normal distribution for this group. Finally, the skewness value of the control group is -.24 in pre-test, .29 in post-test, and .63 in follow-up. Since skewness value of this group also is between -2 and +2 , we can state that there is normal distribution of peer rejection in this group in pre-test, post-test, and follow-up. Levene test is applied for measuring homogeneity of variances. The result revealed that homogeneity assumption was met for peer rejection in pre-test $(\mathrm{F}=.70)$ and $p$-value $(p=.55)$, in post-test $(\mathrm{F}=2.52)$ and $p$-value $(p=.61)$, and in follow-up $(\mathrm{F}=1.52)$ and $p$-value $(p=.21)$. It means that $p>.05$. Thus, the variance of peer rejection for group with MC program, group with BBPT program, group with combination of $\mathrm{MC}$ program and BBPT program, and control group in pre-test, post-test, and follow-up is equal and there is no significant difference between four groups. Comparing mean score of peer rejection in pretest was conducted in order to indicate there is homogeneity for the groups before the interventions.

The descriptive statistic in this study contains percentage, mean, and standard deviation. In order to compare the mean scores of more than two groups One Way- analysis of variance is used. When all participants of random sample are evaluated under various situations, the Repeated measure Anova is used. Thus, Repeated measure Anova is utilized in this study. For accuracy, confidence interval of the study is set up at $p<.05$.

After the administration of the instruments, the collected data are scored and are organized to facilitate the analysis. Collected data were analyzed by running the Statistical Package for the Social Science program (SPSS Version 18.0, for Windows Seven). Through using SPSS, the data systematically are scored.

\section{Results}

The descriptive statistic of the children is demonstrated that 46 , 47,43 , and 34 of them had 8,9 , and 10 years old. The percentage of children of that age includes $33.85,34.55$, and $31.60 \%$ respectively. In addition, $65 \%$ of the children were male and $34.6 \%$ of children were female.

All the children in this study received the diagnosis of moderate severity and childhood-onset type of Conduct Disorder by the psychiatrist based on DSM-V criteria through the structured clinical interviews. In addition, in CBCL, there are specific questions that recognize the Conduct Disorder and its' severity. The sum score for this item is different for male and female. Those children who earned the moderate severity of Conduct Disorder classified as the borderline clinical range. All children received the moderate severity of $\mathrm{CD}$; it 
means that the sum score range for them should be between 5-6 and 4-7 for male and female respectively. All the children received the range between 5-6 and 4-7 for male and female respectively.

All the parents of 136 children filled out the demographic questionnaire. Mothers of all children participated in this study and answered this questionnaire.

The age range for most of the parents was between 30-40 years old in all four groups. Totally, the age range of $21.32 \%$ of them was under 30 years old, $56.62 \%$ between 30 and 40 , and $22.06 \%$ older than 40 years old. For the educational levels of parents, those who had the master or higher degrees were in the minority with $8.83 \%$ (only 12 persons) in comparison with other levels of education. In contrast, parents with the bachelor degree were in the highest for the level of education with $72.79 \%$ (99 persons). Based on the demographic statistics, nearly more than half of mothers $(62.5 \%)$ of children were housekeepers in this study. Only $37.5 \%$ of parents had a position of job in four groups.

Parents asked to fill out the range of their socio-economic in three levels of weak, middle, good, and very good. Most of the parents $(72.79 \%$ of parents) were in the middle level of socio-economic. In contrast, only one $(2.9 \%)$ of the parents in the group four and two (5.9\%) parents of children in group one had the weak situation. Descriptive statistics about the level of knowledge of Conduct Disorder among parents demonstrated that most of the parents in group one, $21(61.8 \%)$ had the weak level of knowledge of Conduct Disorder. 18 parents $(52.9 \%)$ in group three, mentioned that they had the middle level of knowledge about this disorder to their children. Only one parent in group one (2.9 $\%)$, four parents (11.8\%) in group two and group four had the good level of knowledge for Conduct Disorder. Totally, parents' knowledge level for CD are assessed as weak level by 65 parents (47.79\%), middle level by 62 parents (45.59\%), and good level by nine parents (6.62\%).

As it is demonstrated in Table 1, the means on the post-test and follow-up of the Making Choices program, Barkley Behavioral Parent Training, and combination of MC and BBPT decreased. The mean scores of peer rejection in children of the first group that received Making Choices program decreased dramatically from pre-test to posttest. The mean scores dropped from the post-test to follow-up as well. Peer rejection of children in group two that parents of children received BBPT declined from pre-test to post-test and post-test to follow up with a downward trend. However the mean scores of peer rejection in group three had the dramatic fall from 4.53 to 1.18 between pre-test

\begin{tabular}{|l|l|c|c|c|}
\hline \multirow{5}{*}{ Pre-test } & Group & Mean & Std. Deviation & N \\
\hline \multirow{5}{*}{ Post-test } & MCP & 4.51 & .16 & 34 \\
\cline { 2 - 5 } & BBPT & 4.45 & .13 & 34 \\
\cline { 2 - 5 } & Combination of two program & 4.53 & .15 & 34 \\
\cline { 2 - 5 } & CONTROL & 4.48 & .16 & 34 \\
\cline { 2 - 5 } & Total & 4.49 & .15 & 136 \\
\cline { 2 - 5 } & MCP & 2.23 & .22 & 34 \\
\cline { 2 - 5 } & CBPT & 2.32 & .17 & 34 \\
\cline { 2 - 5 } & Combination of two program & 1.18 & .14 & 34 \\
\hline & Control & 4.59 & .19 & 34 \\
\hline \multirow{2}{*}{ Follow-up } & MCP & 2.58 & 1.26 & 136 \\
\hline & BBPT & 1.17 & .16 & 34 \\
\hline & Combination of two program & 1.17 & .163 & 34 \\
\hline & Control & 4.48 & .124 & 34 \\
\hline & Total & 1.99 & 1.45 & 136 \\
\hline
\end{tabular}

Table 1: Descriptive statistic of peer rejection for pre-test, post-test and follow-up test in all intervention methods and control group.

\begin{tabular}{|c|c|c|c|c|c|}
\hline Source & Sum of Squares & Df & Mean & $\mathbf{F}$ & $\boldsymbol{p}$ \\
\hline Test & 465.38 & 1 & 232.69 & 8769.17 & .000 \\
\hline Test * Group & 178.74 & 6 & 29.79 & 1122.69 & .000 \\
\hline Error & 7 & 264 & .02 & & \\
\hline
\end{tabular}

Table 2: Repeated measure anova for peer rejection of children with Conduct Disorder.

and post-test and a very slight reduction from post-test to follow-up.

Two-way Repeated Measure ANOVA was conducted to find out statistically significant effect of groups across test on peer rejection among children with CD across pre-test, post-test, and follow-up. Mauchly's test assumption for sphericity was violated for peer rejection $\left(x^{2}(2, .05)=8.332, p>.05\right)$. So, to evaluate the effect of interaction, $F$ value was calculated based on sphericity assumption $(\mathrm{F}(6,264)=$ 1122.64, $\left.p<.05, \eta^{2}=.962, \mathrm{f}=5.03\right)$. As can be seen from Table 2 the $p$ value is .000 which means less than .05 . It means that the average of mean scores for peer rejection across time (test) was significantly different among four groups. In conclusion, the null hypothesis is rejected. (Table 2)

Post-hoc pairwise comparison was conducted to discover the significant difference of the groups based on the interventions. The following Table describes the results of comparing scores between the three experimental groups in pre-test, post-test, and follow-up.

Table 3 describes the differences between the mean of peer rejection between four groups of the study to follow-up the significant interaction in pre-test, post-test, and follow-up in pairs (6 different pairs for each experimental and control group). According to above Table, differences in mean scores of peer rejection between groups were not significantly different because the $p$ value in all pairs of between groups is more than .05 in pre-test. However, after conducting the interventions in post-test, since the $p$ value founded less than .05 , differences in means of peer rejection between group 1 and group 2 (MCP-BBPT programs), group 1 and group 3 (MC and combination of both programs), and group 3 with group 2 (combination of both programs and BBPT) were significantly different. It is indicated that difference in means of peer rejection between group 1 and group 3 was lower than difference in means of peer rejection between group 1 and group 2. Table 3 shows that although the difference in means of peer rejection was .029 between group 2 and group 3 (BBPT and control group), the difference decreased at the time of follow-up. The other result of this Table demonstrated that the difference in means of peer rejection between group 1 and group 3 (MC and combination of both programs) was lower than the difference between group 1 and group 2 (MC program and BBPT).

In addition, level of significance in control group with other three groups was more than .05. It means that the differences between means of peer rejection in control group with the other three groups in pairs are not significant. According to the results of Table 3 in follow-up, the difference between group 1 and group 2 (MC-BBPT programs) was not significant because the $p$ value founded more than .05 . It can be seen that the difference between control group and group 1 (MCP) is significant at.000. Furthermore, the difference in means of peer rejection between control group and group 2 (BBPT), and the difference between control group and group 3 (combination of both programs) are significant at .000

Table 4 demonstrated post-hoc pairwise comparison to find the significant difference of peer rejection within groups pre-test, post-test, and follow-up in pairs. 


\begin{tabular}{|l|l|l|c|c|c|}
\hline $\begin{array}{l}\text { Peer } \\
\text { Rejection }\end{array}$ & (I) Group & (J) Group & $\begin{array}{c}\text { Mean } \\
\text { Difference } \\
\text { (I-J) }\end{array}$ & $\begin{array}{c}\text { Std. } \\
\text { Error }\end{array}$ & $\boldsymbol{P}$ \\
\hline Pre-test & MCP & BBPT & .059 & .037 & .120 \\
\hline & MCP & Combination of two programs & .0025 & .0037 & .509 \\
\hline & BBPT & Combination of two programs & .083 & .037 & .027 \\
\hline & Control & MCP & .029 & .037 & .433 \\
\hline & Control & BBPT & -.029 & .037 & .436 \\
\hline & Control & Combination of two programs & .054 & .037 & .450 \\
\hline Post-test & MCP & BBPT & .093 & .045 & .041 \\
\hline & MCP & Combination of two programs & 1.044 & .045 & .000 \\
\hline & BBPT & Combination of two programs & 1.137 & .045 & .000 \\
\hline & Control & MCP & 2.36 & .04 & .000 \\
\hline & Control & BBPT & 2.27 & .04 & .000 \\
\hline & Control & Combination of two programs & 3.41 & .04 & .000 \\
\hline Follow-up & MCP & BBPT & 4.044 & .04 & 1.000 \\
\hline & MCP & Combination of two program & .02 & .04 & .55 \\
\hline & BBPT & Combination of two program & .02 & .04 & .55 \\
\hline & Control & MCP & 3.30 & .04 & .000 \\
\hline & Control & BBPT & 3.30 & .04 & .000 \\
\hline & Control & Combination of two program & 3.33 & .04 & .000 \\
\hline
\end{tabular}

Table 3: Mean comparison between four groups in the pre-test, post-test, and follow-up for Peer Rejection (Pairwise comparison).

\begin{tabular}{|l|c|c|c|c|c|}
\hline Group & $\begin{array}{c}\text { (I) Peer } \\
\text { Rejection }\end{array}$ & $\begin{array}{c}\text { (J) Peer } \\
\text { Rejection }\end{array}$ & $\begin{array}{c}\text { Mean } \\
\text { Difference (I-J) }\end{array}$ & Std. Error & P \\
\hline MCP & Pre-test & Post-test & 2.28 & .04 & .000 \\
\hline & Pre-test & Follow-up & 3.33 & .03 & .000 \\
\hline BBPT & Post-test & Follow-up & 1.05 & .04 & .000 \\
\hline & Pre-test & Post-test & 2.13 & .04 & .000 \\
\hline Combination of & Pre-test & Follow-up & 3.28 & .036 & .000 \\
\hline two programs & Post-test & Follow-up & 1.14 & .04 & .000 \\
\hline & Pre-test & Post-test & 3.35 & .04 & .000 \\
\hline Control & Post-test & Follow-up & .034 & .04 & .410 \\
\hline & Pre-test & Post-test & .11 & .04 & .007 \\
\hline & Pre-test & Follow-up & .000 & .03 & .994 \\
\hline & Post-test & Follow-up & .11 & .04 & .007 \\
\hline
\end{tabular}

Table 4: Mean comparisons between pre-test, post-test, and follow-up in four groups for peer rejection.

According to Table 4 the difference in means of peer rejection pretest and post-test, pre-test and follow-up, and post-test and follow-up is statistically significant for the first group that received MCP. It is because the significant level reported as less than .05 . The situation was same for the second group that received BBPT. The difference in means of peer rejection between pre-test and follow-up for group three that received combination of both programs is significant at the .000 . However, the difference in means of peer rejection between post-test and follow-up for group three is not significant.

As can be seen from Table 4, the difference in means of peer rejection between pre-test and post-test in group 3 (combination of both programs) was lower than difference in means of peer rejection between pre-test and post-test in group 4 (control group). Moreover, the difference in means of peer rejection between post-test and followup in group 3 was lower than the difference in means of peer rejection between post-test and follow-up in group 1 and group 2 .

The above Figure 1 shows fluctuations in mean scores of peer rejection in four groups. The mean scores of peer rejection in the first group that children received Making Choices program, showed the rapid reduction from pre-test to post-test and gradual decrease from post-test to follow-up. The situation of group two that only parents of children received BBPT is also same as the first group with the sharp decline from pre-test to post-test and slight decrease from post-test to follow-up. However, conducting a combination of both programs in third group presented noticeable reduction in mean scores of peer rejection compare to group one and two from pre-test to post-test. Though, the mean scores of peer rejection in this group declined very slightly from post-test to follow-up. The mean scores of peer rejection for all groups one, two, and three in follow-up stood on the same level. As can be seen from the figure, the control group that is group four did not have any changes in mean scores of peer rejection from pre-test to post-test and follow-up and showed a flat trend during the study.

\section{Discussion and Conclusion}

The results of this study showed three kinds of interventions include Making Choices program, Barkley Behavioral Parent Training, and combination of both MC and BBPT which are based on CognitiveBehavioral intervention and Behavioral Parent Training decreased the peer rejection of children with Conduct Disorder.

As it mentioned above, to evaluate the effect of interaction, F value was calculated based on sphericity assumption $(\mathrm{F}(6,264)=1122.64, p$ $\left.<.05, \eta^{2}=.962, \mathrm{f}=5.03\right)$. As can be seen from Table 2 the $p$ value is .000 which means less than .05. It showed that the average of mean scores for peer rejection across time (test) was significantly different among four groups. So, it concluded that peer rejection of Children with CD, aged 8-10 years changed when they participate in group MCP in first group, or their parents participate in group with BBPT, or children and their parents participate in the combination of both programs.

This study suggests that combination of Making Choices program and Behavioral Parent Training of Barkley is very effective for the peer rejection of children with Conduct Disorder particularly in the time of post-test of the study. The time of follow-up showed that effects of a combination of the two programs resulted in remaining the reduction of peer rejection in same level for children with Conduct Disorder. Another finding of this study revealed that although the combination of MC program and BBPT decreased peer difficulties of children more than MC program or BBPT separately in time of post-test, the changes in peer rejection of children stood on the same level in time of follow-up

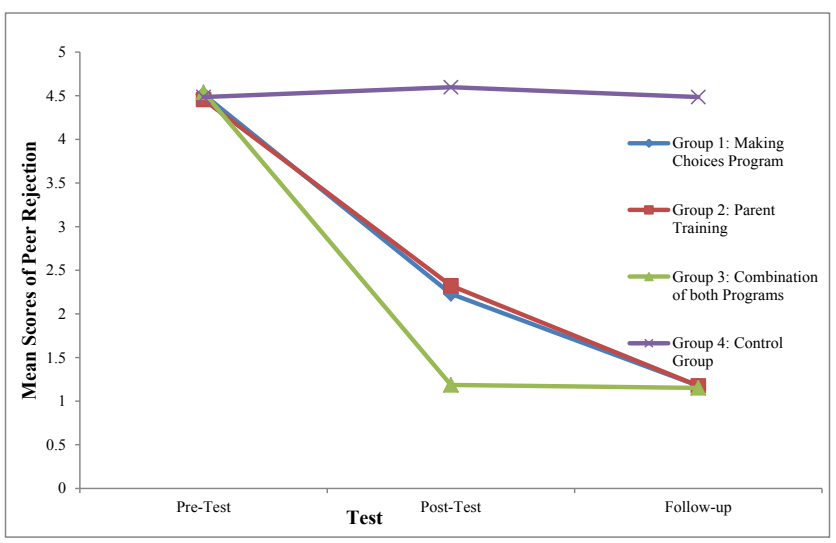

Figure 1: Mean scores of peer rejection in four groups across pre-test, posttest, and follow-up. 
for three groups. Thus, MC program, BBPT, and combination of both programs are suggested for peer rejection of children with childhoodonset type of CD in long period of time.

According to Social cognitive theory of Bandura, children learn to notice more clues in different social situation and not only noticing to those clues that suggest they are threatened. Thus, they learn how to build critical cognitive skills [42]. According to this theory, child's expectation of parents, teachers, and opportunities effect on using schema that stored in long-term memory as social cues. When children are able to understand the social cues, emotions, and others' intention; it helps to the progress of social development with the real interpretation of peer's intentions.

The result of this study was in harmony with some previous studies. The fast track program is a kind of social cognitive intervention same as Making Choices program. This program has two components include universal and selective component. In one study, this program was educated with children in Grade 1 with social skills training, family intervention, and academic assistance. The effects on students caused decreases in social problems and improvement in positive interaction with peers. In addition, their parents reported progress in parent-child interactions at home [43]. The other study conducted for the examining Making Choices program with six-month follow-up between aggressive children and suggested of decreasing in improving positive behavior for them [14]. Tuisarkani-Ravari found that social skills training based on story telling effect on behavioral problems and improvement in social skills, especially relationship with peers for girls with CD between 10 and 11 years old [26]. Furthermore, this study reported that aggressive behavior and hostile behavior decreased between participants.

BBPT [24] that is based on social learning theory emphasizes on changing the variables in a child's situation. This program focuses on social learning principles for changing the coercive style of parents. When parents learn appropriate behavior in terms of discipline approaches for considering the time for their children, ignoring misbehavior, using time out as punishment, and other clear rules in the family; children observe their parent behavior and modeled their behavior. Moreover, family harmony increases inside the family that result in acceptable parenting style, better parent-child relationship, and appropriate behavior of children.

According to literature, one study found behavioral parent training (Incredible Years) was effective in the improvement in interpersonal relationships of children with Conduct Disorder at school [20]. Similarly, Odgen and Hagen examined the effect of behavioral parent training among children with Conduct Disorder between 4 to 12 years old [44]. The results showed improvement in social relationship between parents and peers. The result of this study about effects of behavioral parent training was in harmony with the other study [22]. This study also suggested that conducting three programs of Triple P (Enhanced-Level 5, Standard-Level 4, and Self-Directed-Level 4) decreased disruptive behavior of children. In addition, based on metaanalysis of 80 investigations, Parent Management Training for children and adolescents results in positive relationship with peers, especially for younger children [45]. Salehi indicated that parent training based on Adlerian approach between mothers of children with CD results in decreasing the severity of Conduct Disorder with childhood-onset type in Iran [30].

In confirming the above results, the other study examined the effect of parent management training and Problem-solving Skills Training on symptoms of children with CD in Isfahan/Iran between 40 male pupils between 10 to 11 years old [29]. The result of this study demonstrated that parent management training decreased the symptoms of CD. However, Problem-solving Skills Training did not have any effect on symptoms of $\mathrm{CD}$. The combination of the two programs was also effective for symptoms of CD in participants.

Social learning theory explains that modifying child's social environment results in changing aggressive behavior of children and decline child's interpersonal difficulties. In addition, CBT helps children with $\mathrm{CD}$ to manage the aggressive behavior, handle frustration, and regulate their emotions in order to select proper reaction in a social situation. Children are encouraged to practice in different social situation, to identify adaptive responses. When children received the $\mathrm{MC}$ program or their parents participated in BBPT, children's problems in terms of peer rejection and aggression decreased. However, the third group of this study that children were participated in MC program and their parents joined to BBPT program, showed impressive effects in decreasing peer rejection and aggression. It is because whole environment of family changed and received education. Parents of children learn about effective methods of discipline and understand how children observe them and modeled their behavior. They find how to encourage positive behavior of children by rewards and manage non-compliance of children by suitable punishment.

On the other hand, children identify the social cues not only related to aggression, but also notice to body language and tone of voice, learn how to interpret peers' intention correctly and pursue goals related to specific social situation. As both parents and children received the intervention, so the whole environment of family changed, and it leads to more effective results on children's peer rejection.

Based on review literature, Conner and Fraser examined the effect of Making Choices program plus strong families program among pre-school children. The combination of two programs influenced on decreasing aggression and peer acceptance of children [15]. Moreover, in consonance with the outcomes of this study, another study examined the effects of Making Choices program and Making Choices program with the strong families program for parents on elementary school-age children and indicated of differences among children in interpreting of social cues in social situations without hostile, setting prosocial goals for themselves, and generate responses [46].

A noticeable point about this study is the format of four groups. As mentioned in the introduction of the study, Making Choices program was used alone or with the Strong Families program in previous studies (to improve parenting skills). However, other scholars suggested enhancing more in-depth and less costly parent training, particularly for high risk-children. In addition, no other studies examined the effects of Behavioral Parent Training of Barkley separately on peer rejection among children with $\mathrm{CD}$ and compare it to Making Choices program and combination of the two programs $[13,14,20]$.

The findings can support that Making Choices program helped children with $\mathrm{CD}$ to manage peer interaction, respond positively to new social situations and think about alternative responses. It is suggested that Behavioral Parent Training intervention is effective when children with Conduct Disorder are younger. While children grow to adolescence, the effect of parent training decreases [7]. As can be seen in this study children with childhood-onset type were chosen to see the effect of the program. Parents of these children need to improve their information about this disorder to help children how to solve social problems.

In overall, this study found that the combination of both programs 
is more effective in a short period of time. However, both kinds of interventions decreased peer rejection of children with Conduct Disorder in a long period of time.

According to the results of this study, the following suggestions are for future studies in order to expand this research. First, it is suggested that this study duplicate among boys and girls with Conduct Disorder separately to compare the effect of the programs among them on their peer rejection. Second, it is suggested that the effect of three programs examines on other symptoms of children with Conduct Disorder. The third suggestion is to perform a research to examine the effect of Making Choices program and parent training among preadolescents with Conduct Disorder and see the result of programs on their peer difficulties. The other suggestion is to add qualitative research to this study. The daily experience of each participant (parent and children) outside the group session may be different from one another. So one of the limitations of the study is that since there is not complete control of sources of information such as TV programs, books, or magazines for parents, then peer's influences to children who might have an influence on the final results. This study was limited due to the participation of children and parents of them. It is recommended to carry out an investigation and compare the teacher and parent rating on symptoms of children with Conduct Disorder. Beside above limitations, the short amount of time of the therapeutic interventions, as well as the considerations linked to the non-perfect equivalence of the different subgroups, are the other restrictions of the study that should be considered.

\section{References}

1. American Psychiatric Association (2013) Diagnostic and statistical manual of mental disorders. (5th edn), Washington DC

2. American Psychiatric Association (2013) Cautionary statement for forensic use of DSM-5. In Diagnostic and Statistical manual of mental disorders. ( $5^{\text {th }}$ edn).

3. Pratt M, Smith M, Reigelsperger R, O'Connor LV, Saum C, et al. (2003) Psychosocial treatment alternatives for adolescents with conduct problems. Journal of Psychological Practice 8: 1-13.

4. Azadyekta M (2011) Prevalence of Conduct Disorder among Elementary Students in Tehran City. Procedia-Social and Behavioral Sciences 29: 693702

5. Raine A, Moffitt TE, Caspi A, Loeber R, Stouthamer-Loeber M, et al. (2005) Neurocognitive impairments in boys on the life-course persistent antisocial path. J Abnorm Psychol 114: 38-49.

6. Fergusson DM, Swain-Campbell NR, Horwood LJ (2002) Deviant peer affiliations, crime and substance use: A fixed effects regression analysis. J Abnorm Child Psychol 30: 419-430.

7. Kazdin AE (2002) Psychosocial treatments for conduct disorder in children and adolescents. A guide to treatments that work 2: 57-85.

8. Lavin MR, Rifkin A (1993) Diagnosis and pharmacotherapy of conduct disorder Progress in Neuro-Psychopharmacology and Biological Psychiatry 17: 875885

9. Van de Wiel N, Matthys W, Cohen-Kettenis P, Van Engeland H (2002) Effective treatments of school-aged conduct disordered children: Recommendations for changing clinical and research practices. Eur Child Adolesc Psychiatry 11: 7984.

10. Kazdin AE (2008) Evidence-based treatment and practice: new opportunities to bridge clinical research and practice, enhance the knowledge base, and improve patient care. Am Psychol 63: 146-159.

11. Middleton MB, Cartledge G (1995) The effects of social skills instruction and parental involvement on the aggressive behaviors of African American males. Behav Modif 19: 192-210.

12. Maughan B, Rowe R, Messer J, Goodman R, Meltzer H (2004) Conduct disorder and oppositional defiant disorder in a national sample: developmental epidemiology. J Child Psychol Psychiatry 45: 609-621.
13. Fraser MW, Nash JK, Galinsky MJ, Darwin KM (2002) Making choices: Social problem-solving skills for children: ERIC.

14. Fraser M.W, Lee JS, Kupper LL, Day SH (2011) A controlled trial of the Making Choices program: Six-month follow-up. Research on Social Work Practice 21 165-176.

15. Conner NW, Fraser MW (2011) Preschool Social-Emotional Skills Training A Controlled Pilot Test of the Making Choices and Strong Families Programs. Research on Social Work Practice 21: 699-711.

16. Snyder JJ, Patterson GR (1995) Individual differences in social aggression: A test of a reinforcement model of socialization in the natural environment Behavior Therapy 26: 371-391.

17. Kazdin AE (2005) Parent management training: Treatment for oppositional, aggressive, and antisocial behavior in children and adolescents. Oxford University Press.

18. McMahon RJ, Forehand RL (2005) Helping the noncompliant child: Familybased treatment for oppositional behaviour. Guilford Press.

19. Shaw DS, Owens EB, Giovannelli J, Winslow EB (2001) Infant and toddler pathways leading to early externalizing disorders. J Am Acad Child Adolesc Psychiatry 40: 36-43.

20. Webster-Stratton C, Reid MJ, Hammond M (2004) Treating children with earlyonset conduct problems: Intervention outcomes for parent, child, and teache training. J Clin Child Adolesc Psychol 33: 105-124.

21. Sanders MR (199) Triple P-Positive Parenting Program: Towards an empirically validated multilevel parenting and family support strategy for the prevention of behavior and emotional problems in children. Clin Child Fam Psychol Rev 2 : 71-90.

22. Sanders MR, Bor W, Morawska A (2007) Maintenance of treatment gains: a comparison of enhanced, standard, and self-directed Triple P-Positive Parenting Program. J Abnorm Child Psychol 35: 983-998.

23. Barkley RA (1999) Response inhibition in attention $\square$ deficit hyperactivity disorder. Mental Retardation and Developmental Disabilities Research Reviews 5:177-184.

24. Barkley RA (1997) Defiant children: A clinician's manual for assessment and parent training. Guilford Press.

25. Baedi Z (2001) The effects of play therapy based on cognitive-behavioral therapy on decreasing aggression among children with conduct disorder. Journal of Thought and Behavior 25: 111-112.

26. Tuisarkani-Ravari M (2008) Effects of teaching social skills based on story telling on the symptoms reduction of girl-children with conduct disorder aged 10 and 11 years old. University of wlfare science and rehabilitation, Iran. (Unpublished data)

27. Ghaderi N, Asghari-Moghadam M, Shaviri M (2006) Effect of cognitive behavioral play therapy on aggression among children with Conduct Disorder. Journal of scholar and behavior 19:75-84.

28. Rajabpour M, Makvand-Hoseini S, Rafinia P (2011) Effects of group therapy in parent-child relationship training on aggression in pre-school children. Journal of clinical psychology 13: 65-74.

29. Lali M, Malekpour M, Molavi $H$, Abedi A, Asgari K (2012) The effects of paren management training, problem-solving skills training and the eclectic training on conduct disorder in Iranian elementary school students. International Journal of Psychological Studies 4: 154.

30. Salehi S (2005) Effects of parent training based on Adlerian approach of mothers with conduct disorder children on their coping methods. Allameh Tabatabai University. (Unpublished data)

31. Scott S (2007) Conduct disorders in children. BMJ 334: 646-648.

32. Robins LN (2006) Conduct disorder. Journal of Child Psychology and Psychiatry 32: 193-212.

33. Ary D, Jacobs L, Sorensen C, Walker D (2013) Introduction to research in education: Cengage Learning.

34. Achenbach T, Rescorla L (2001) Manual for the ASEBA school-age forms \& profiles: an integrated system of multi-informant assessment Burlington, VT: University of Vermont. Research Center for Children, Youth, \& Families.

35. Minai A (2005) Manual of ASEB school-age forms for Iranian children. Research 
Citation: Salehi S, Ghanbari S, Shaban S, Pooravari M (2014) Peer Rejection among Children with Conduct Disorder: Compare Cognitive-Behavioral Therapy and Behavioral Parent Training. Arts Social Sci J 5: 070. doi: 10.4172/2151-6200.1000070

Page 9 of 9

Institution for Exeptional Children. Tehran.

36. Tahmasian K (2005) Finding model for self-efficacy for adolescents' depression based on Bandura Theory. University of Rehabilitation, Iran. (Unpublished data)

37. Rahmati B (2007) Studying the effects of training life skills on social adjustment of children in 4th grade of elementary school (Master), University of Shahid Beheshti, Iran. (Unpublished data)

38. Crick NR, Dodge KA (1994) A review and reformulation of social informationprocessing mechanisms in children's social adjustment. Psychological bulletin 115: 74 .

39. Matthys W, Cuperus JM, Engeland HV (1999) Deficient social problem-solving in boys with ODD/CD, with ADHD, and with both disorders. J Am Acad Child Adolesc Psychiatry 38: 311-321.

40. Morgan GA, Leech NL, Gloeckner GW, Barrett KC (2004) SPSS for introductory statistics: Use and interpretation. Psychology Press.

41. Pallant J (2010) SPSS survival manual: A step by step guide to data analysis using SPSS. McGraw-Hill International.
42. Bandura A (1986) Social foundations of thought and action: a social cognitive theory. Englewood Cliffs: NJ: Prentice-Hall.

43. Slough NM, McMahon RJ (2008) Preventing serious conduct problems in school-age youth: The Fast Track program. Cogn Behav Pract 15: 3-17.

44. Ogden T, Hagen KA (2008) Treatment effectiveness of parent management training in Norway: a randomized controlled trial of children with conduct problems. J Consult Clin Psychol 76: 607-610.

45. Harris KE (2007) A Meta-analysis of parent management training outcomes for children and adolescents with conduct problems: Parenting Children with Disruptive Behaviors Problems. University of Toronto, Canada. (Unpublished data)

46. Fraser MW, Galinsky MJ, Smokowski PR, Day SH, Terzian MA, et al. (2005) Social information-processing skills training to promote social competence and prevent aggressive behavior in the third grades. J Consult Clin Psychol 73: 1045-1047. 